\title{
Trajetórias e interesses: os EUA e as finanças globalizadas num contexto de crise e transição
}

\author{
JAIME CÉSAR COELHO*
}

Interests and international relations trajectories: the US and the global finances in a context of crises and transition. This paper aims to analyze the elements of continuity and discontinuity in American foreign policy from the nineties. In this regard, it emphasizes the importance of financial issues within the scope of the U.S. government strategies for foreign integration and tries to analyze comparatively the Republicans and Democrats government of the period, ending with some prospective questions concerning the Democratic government of President Obama in the context of international economic crisis.

Keywords: U.S.A; foreign policy; international financial reform; crisis; transition. JEL Classification: F50.

O primeiro elemento de destaque deste artigo tem como referência uma questão metodológica: a busca de continuidades e rupturas em termos de política externa. Esta busca nos orienta, do ponto de vista analítico, na definição de padrões de comportamentos que possibilitem identificar estratégias de ação, o que é fundamental em jogos de interações estratégicas assimétricas (Axelrod e Keohane, 1985), num Sistema de Estados hierárquico e em transição, no que tange aos aspectos de sua mobilidade vertical. O segundo elemento, ainda do ponto de vista metodológico, diz respeito ao ator escolhido para a análise, qual seja, os EUA. A escolha dispensa comentários, pois trata-se de ator-chave no cenário das disputas interna-

\footnotetext{
* Professor do Departamento de Economia e Relações Internacionais da Universidade Federal de Santa Catarina. E-mail: findariver@gmail.com. O presente artigo foi apresentado no final de novembro de 2008 em seminário do Projeto Renato Archer sobre a Política Externa Americana. Agradecemos a contribuição dos pesquisadores desse projeto, salientando que as opiniões aqui apresentadas são de única responsabilidade do autor. Agradecemos também a contribuição dos bolsistas de iniciação científica do Núcleo de Economia e Política Externa da UFSC, Bruno Mazzucco e Felipe Gaiotto. Submetido: 5/jun./2009; Aprovado: 3/set./2010.
} 
cionais. O terceiro elemento metodológico implica pensar o Sistema de Estados por meio de uma interação entre a dimensão interna e externa dos Estados Nacionais, o que resulta na negativa de que os atores estatais são "black boxes" (premissa adotada pelo realismo estrutural). O quarto e último aspecto metodológico trata do campo de análise deste artigo, que se situa na fronteira da literatura da Economia Política com as tradições teóricas das Relações Internacionais, portanto, trata-se de um artigo que faz referência a campos que se conectam para composição do que se poderia chamar de Economia Política Internacional (EPI) (Cohen, 2008).

A primeira década do século XXI está chegando ao fim com dois acontecimentos marcantes para os EUA e, como não poderia deixar de ser, para o restante do planeta. O primeiro é a crise financeira e o segundo a eleição do democrata Barak Obama para a presidência da república. O primeiro suscita novamente a discussão sobre a necessidade de uma alteração do regime financeiro inaugurado na era Reagan e o segundo mostra os limites da aventura imperial americana, baseada no unilateralismo e em ações bélicas. No nosso entendimento ambos os eventos não são meros acidentes de percurso, mas a consequência, ou desdobramentos de uma história que diz respeito às alterações e disputas num sistema de Estados em transição.

Os elementos estruturais desse sistema permanecem inalterados: a dinâmica política internacional ainda tem como ator principal o Estado nacional; as relações interestatais continuam a ser marcadas pela polarização e assimetrias de poder e riqueza. Esses aspectos, que denotam a estabilidade sistêmica, não devem ofuscar o fato de que novos entrantes estão em cena e possíveis mobilidades verticais estejam em curso.

A análise do momento atual não poderia deixar de levar em consideração aspectos da história econômica recente dos EUA, bem como de sua posição em termos de poder no sistema de Estados, em especial pelo contraste entre a última década do século XX e a primeira do século XXI.

\section{RETOMADA E AFIRMAÇÃO DA HEGEMONIA AMERICANA}

Os anos 1990 foram fundamentalmente dominados pela administração democrata. Os dois mandatos democratas (janeiro de 1993 e janeiro de 2001) marcaram o período mais próspero, em termos de crescimento contínuo, do pós-segund Guerra. No plano interno o sucesso econômico foi retumbante e no plano externo a nação americana parecia se afirmar como a única superpotência pós-guerra fria. A administração Clinton teve no plano externo uma de suas maiores fontes de sustentação política e, do ponto de vista da política econômica exterior, relevante papel no avanço das reformas liberalizantes nos países periféricos. É importante levar em consideração que a política externa do governo democrata, do ponto de vista econômico, indica uma continuidade do período republicano antecedente e que seria seguida em boa medida pelo governo republicano de Bush II.

Isto nos faz supor que as linhas gerais da orientação externa em termos de política econômica, consubstanciadas nos programas de ajustamento das instituições 
financeiras multilaterais (FMI e Banco Mundial) tiveram um caráter estruturante na posição internacional dos EUA dentro do sistema de Estados. Os programas de ajustamento estabeleceram uma orientação deflacionista e liberalizante mundo afo$\mathrm{ra}$, abrindo a era das privatizações e fusões. Esses programas, tanto os de primeira como os de segunda geração, marcaram um padrão de relacionamento entre a política externa estadunidense, as IFMs e os demais atores estatais soberanos. Lembremos que a década de 1980, depois do choque de juros de Paul Volcker (final do governo Carter), alterou favoravelmente para os EUA a dinâmica econômica internacional. Num certo sentido, o governo democrata dos anos 1990 foi beneficiário do período republicano anterior, em especial pelo papel desempenhado pelo governo Reagan na retomada da hegemonia americana. Se esse governo foi o período da retomada da hegemonia, o governo Clinton foi o período de sua afirmação.

A retomada da hegemonia americana (Conceição, 1997) foi marcada por dois períodos que se alinham ao final do governo Carter e aos dois mandados do presidente Reagan. Num primeiro momento (1979-1985) a valorização do dólar, provocada pelo choque de juros de Paul Volcker, resultou numa recessão mundial que duraria até 1983, realocando a liquidez internacional em direção às necessidades de financiamento do Tesouro americano. A conformação de um regime monetário internacional tendo como moeda de referência o dólar propiciava ao governo americano a vantagem de cobrir seus passivos externos na própria moeda de emissão. Dessa forma, a política monetária americana servia como elemento estratégico na conformação do poder econômico relativo da superpotência. Seus efeitos colaterais são bem conhecidos: a elevação dos juros levou à recessão mundial e países com fortes passivos externos foram tragados pelo turbilhão do enxugamento da liquidez externa (o caso latino-americano foi emblemático nesse sentido) e pela deflação nos preços das commodities que corroeu suas receitas de exportação.

Esses eventos produziram os primeiros programas de ajustamento estrutural levados a cabo pelas Instituições Financeiras Multilaterais e que enquadrariam as políticas econômicas dos países periféricos à onda liberalizante que sopraria na esfera internacional a partir dos anos 1980 . O enquadramento deu-se paralelamente à expansão das praças financeiras offshore e desregulamentação das restrições ao livre movimento do capital.

Saliente-se que o processo de desregulamentação é acompanhado por um intenso movimento de inovações financeiras, que, de um lado aumentaram progressivamente a liquidez internacional, de outro produziram o efeito de aumentar o risco sistêmico ${ }^{1}$. A expansão financeira dá-se pela inovação (propiciada pela melhoria tecnológica e pelas alterações normativas no regime de acumulação) que dificulta o controle da expansão do crédito em função da expansão de operações complexas nos mercados de títulos domésticos e externos que passam a se conectar. Também fundamentais foram as alterações institucionais, permitindo às organizações financeiras operar em vários mercados tanto em termos de produtos como espacialmen-

\footnotetext{
${ }^{1}$ Ver a Hipótese da Instabilidade Financeira em Minsky (1992).
} 
te (no caso dos EUA, a progressiva desconstrução do Glass Steagal Act é o exemplo de destaque). Os mercados são internacionalizados e integrados, o que conduz ao aumento da interdependência das políticas macroeconômicas, porém, a hierarquia no plano das moedas tende a produzir ganhos assimétricos, tanto pela origem dos fundos de investimento (oferta de liquidez), quanto pela capacidade relativa dos Estados Nacionais em responder ao aumento na volatilidade dos preços por meio de suas políticas soberanas de gestão da moeda e de seus passivos e ativos.

Observe-se que a retomada da hegemonia americana vem acompanhada pela distribuição assimétrica dos custos e benefícios dos ajustes iniciados a partir da diplomacia do dólar forte.

Essa retomada não seria possível sem que de um lado o sistema oferecesse perspectivas de ganhos (potencializadas pelo aumento do comércio internacional, pelas oportunidades de aquisições patrimoniais e pela valorização do capital na esfera financeira) para os agentes econômicos dos países desenvolvidos e para os emergentes (em especial do Leste Asiático) e de outro, um forte enquadramento de parte da periferia que fora presa do choque de liquidez do início dos anos 1980.

Para os EUA, embora a valorização do dólar produzisse um efeito negativo na balança comercial, havia uma clara vantagem, sendo este o país emissor da moeda em que seus passivos estavam denominados: ver o custo desse passivo diminuir; no mesmo sentido o dólar valorizado provocava um ajuste forçoso na produtividade interna, barateando os custos da tecnologia importada e contribuindo para um freio no processo inflacionário (importações mais baratas, com deflação no preço do petróleo e nas commodities industriais). Ressalta-se o fato de que a desregulamentação financeira dava aos EUA a vantagem comparativa de emitir a moeda de curso internacional, na qual os contratos são denominados, e de possuir o mercado financeiro mais profundo de todo o sistema internacional. É imperioso reconhecer que essa dinâmica foi de grande valia para a economia americana e para a recuperação de seu status político no cenário internacional.

O índice de preços ao consumidor nos EUA caiu de 9\% (dez-dez/1980-1981) para 1,1\% (dez-dez/1985-1986). A taxa dos Federal Funds caiu de 16,39\% em 1981 para $6,80 \%$ em 1986, bem como a taxa dos títulos do Tesouro americano (10 years) de 13,92\% para 7,67\% no mesmo período. A retomada do crescimento americano foi constante entre 1983 e 1988, último ano do governo Reagan, totalizando um crescimento médio de 4,46\% a.a. A taxa de desemprego que atingira 9,7\% da força de trabalho americana em 1982 recuou para 5,5\% em 1988 (ver gráficos nos anexos do final do texto).

A recuperação econômica afirma ideologicamente a era liberal e enfraquece as políticas intervencionistas, espalhando mundo afora programas de ajustamento estrutural e de reforma do Estado. Embora na esfera financeira, até meados dos anos 1990, tenhamos assistido a vários episódios de instabilidade, os ganhos produzidos em diversas frentes da liberalização pareciam superar seu custo principal: a instabilidade social e econômica. Este fora exportado em grande medida para a periferia do sistema.

O período da diplomacia do dólar forte foi substituído pela desvalorização da 
moeda americana a partir de 1985. Como num pêndulo, a política monetária americana ora fortalece a moeda (necessidade de cobertura dos passivos pelo enxugamento de liquidez internacional), ora desvaloriza seu ativo monetário (aumentando as possibilidades das receitas de exportação). A desvalorização seguiria durante os dez anos seguintes ao acordo do Plaza (1985) e teria como efeito a otimização dos ganhos de produtividade conseguidos durante o período da diplomacia do dólar forte, o que significava tentar diminuir o saldo negativo em transações correntes. $\mathrm{O}$ acordo teve grande impacto por ser um movimento pactuado entre as grandes economias (França, Alemanha, Japão, Inglaterra e EUA) e que coordenava um processo de desvalorização a partir dos três bancos centrais das economias mais fortes do período (EUA, Japão e Alemanha).

A desvalorização do dólar implicava, por parte do Japão, que este aceitasse arcar com parte dos custos de financiamento do déficit em transações correntes dos EUA. À medida que o iene valorizava-se perante o dólar, o dinamismo exportador japonês arrefecia, seus ativos denominados em dólar (parte da dívida americana) perdiam valor e parte dos recursos japoneses migravam da valorização produtiva para a esfera financeira ${ }^{2}$. Vê-se que o movimento pendular da política monetária propiciado pelo controle da moeda de referência internacional mostra seu mecanismo de funcionamento e reafirma o papel das assimetrias de poder, tendo como componente fundamental a hierarquia das moedas ${ }^{3}$.

Em 1987, o segundo acordo (Louvre) coordenado entre as economias centrais consegue estabilizar o valor da moeda americana produzindo nos anos seguintes o soft-lending da moeda americana (Serrano, 2004).

Do ponto de vista financeiro, o governo Reagan segue com os processos de desregulamentação e aumento da liberdade do movimento do capital. Esse processo, como já mencionado, dá-se sob alteração nas legislações nacionais e pela inovação financeira. Esse movimento expressa a disputa pelo capital, que se dá na arena política, por meio dos processos de decisão que levam à desregulamentação progressiva do sistema.

Ao mesmo tempo isso gera uma forma de comportamento econômico que privilegia os ganhos de curto prazo em detrimento dos investimentos de longo prazo.

Cumpre papel relevante o constante endividamento do Estado, cujos títulos estarão na base da pirâmide dos empréstimos estruturados. A riqueza se transfigura em diferentes tipos de ativos e essa transfiguração procura aplacar as restrições impostas pela realização da mercadoria vis-à-vis os processos de valorização desenfreada possibilitados pela esfera financeira (Beluzzo, 1997). Há uma internalização de um padrão sistêmico de produção de riqueza sob o domínio financeiro (Braga, 1997). Os fluxos financeiros excederão em muito os fluxos de comércio e

\footnotetext{
${ }^{2}$ Esse movimento explicaria a expansão da bolha imobiliária japonesa, cujas consequências foram sintetizadas na estagnação japonesa dos anos 1990.

${ }^{3}$ Para uma exploração da questão da hierarquia das moedas ver Prates e Cintra, 2008.
} 
os fluxos de investimento externo direto, muito embora a integração dos mercados estabeleça vínculos de contágio entre as diferentes esferas de valorização (comercial, produtiva e financeira).

A integração financeira é acompanhada por um processo de integração produtiva e comercial potencializando os ganhos do capital, ampliando as escalas de produção, aumentando os níveis de produtividade, mas ao mesmo tempo produzindo uma sensível elevação do risco sistêmico.

A economia americana chegaria ao final do governo Reagan com uma performance invejável. O governo republicano soube tirar proveito de sua posição-chave como emissor da moeda internacional. Tirou proveito também das instituições financeiras de Bretton Woods, que serviram de forma exemplar aos interesses da abertura econômica mundo afora. Fato este facilitado pela crise financeira produzida pelo choque de juros do final do governo Carter.

No plano político, o governo Reagan conseguira enquadrar a América Latina em função dos programas de ajustamento estrutural, empurrar a União Soviética para o abismo com a aceleração dos gastos militares ${ }^{4}$ e o acirramento das contradições internas e fato de grande importância, frear o avanço da economia japonesa com a valorização do iene perante o dólar, posto que o dólar sofreria um processo contínuo de desvalorização entre 1985 e 1995.

Reagan simbolizou a expansão da era do liberalismo econômico pós-Bretton Woods. Uma era que se inicia em 1971 com o fim da conversibilidade do dólar em ouro e que atinge seu ápice a partir dos anos 1980. A liberalização financeira e a importância dessa esfera na retomada da hegemonia americana foi fundamental. Em outras palavras, os interesses financeiros seriam cada vez mais importantes na estratégia da política externa americana, por dois motivos basilares: a expansão dos processos de inovação financeira dá-se tendo o dólar como moeda de referência para a maior parte dos contratos e garante uma ampliação do espaço de valorização para o capital americano offshore. Manter o papel do dólar nas transações internacionais é um aspecto central, se não estruturante, da política de Estado norte-americana, pois permite uma vantagem comparativa em termos de financiamento de suas necessidades que nenhum outro país ou bloco dispõe.

Por meio do manejo da política monetária é possível alterar o valor relativo da moeda, o valor dos débitos, o custo relativo do capital (taxas de juros) e interferir nos fluxos do capital na esfera internacional. Isso efetivamente aumenta o poder de comando do Estado americano na arena política internacional. Desde já é possível afirmar, como veremos adiante, que mudam os governos, mas a posição do governo americano na discussão da arquitetura financeira internacional conti-

\footnotetext{
${ }^{4}$ Os gastos militares americanos cresceram sistematicamente durante o governo Reagan, caindo somente no último ano de mandato. Entre 1981 e 1988 o crescimento médio anual dos gastos governamentais com a rubrica "defesa nacional" foi da ordem de $6,5 \%$ a.a. Esse crescimento foi muito superior aos gastos federais excluindo-se a defesa nacional, que cresceram em média 1,3\% a.a. (dados agregados obtidos a partir do U.S. Department of Commerce - Bereau of Economic Analysis).
} 
nua a mesma. Republicanos ou Democratas, todos foram entusiastas e se serviram da vantagem comparativa de ter o dólar como moeda de curso internacional.

\section{O INTERSTÍCIO DE GEORGE BUSH E OS EXUBERANTES ANOS 1990}

A saída de Reagan foi coroada com chave de ouro. O partido republicano teria seu terceiro mandato consecutivo. Reagan conseguira levar ao poder seu sucessor: George Bush. Se por um lado o novo presidente chegara ao poder por meio do capital político de seu antecessor, por outro teria de fazer frente aos problemas herdados da era Reagan e que se manifestariam fundamentalmente por meio da deterioração do quadro econômico e que custariam sua reeleição.

$\mathrm{Na}$ herança de Reagan estava o crescente déficit público, o persistente déficit em transações correntes e a crise das instituições de poupança. Durante anos o governo Reagan aumentara os gastos com defesa, reduzira impostos e desregulamentara o mercado financeiro, alimentando a bolha de ativos que viria a estourar a partir de 1986. A crise das instituições de poupança esteve associada com a retirada das deduções fiscais sobre passivos do setor imobiliário com o ato da reforma fiscal de 1986, ato este que buscava diminuir os impactos dos cortes de impostos do primeiro mandado de Reagan.

O crescimento anterior dos investimentos imobiliários fora uma combinação de incentivos fiscais e desregulamentação setorial; o que a reforma de 1986 fazia era retirar parte do combustível que dera ímpeto ao crescimento do setor e abria espaço para que o mercado corrigisse o preço dos ativos conforme as expectativas em relação ao carregamento em carteira de passivos a descoberto. O desfecho foi uma diminuição de investimentos e restrição ao crédito, interrompendo o circuito de pagamentos e produzindo a deflação dos ativos.

Exatamente como a legislação bancária de 1981 havia alimentado o boom, a de 1986 acelerou o inevitável colapso. Sem as vantagens tributárias, a bolha do mercado imobiliário estourou. Os preços despencaram, as hipotecas não foram pagas e os especuladores quebraram. [...]; foi preciso quase uma década para que os equívocos do início dos anos $80-$ taxas de juros exorbitantes, desregulamentação negligente e técnicas contábeis extravagantes - se tornassem totalmente claros e precisassem ser enfrentados. Essa foi a herança de Reagan para seu ex-vice-presidente, George H. W. Bush, que teve de socorrer os bancos a um alto custo para o orçamento federal [...]; de uma maneira lenta, foi armado o palco para a recessão que se seguiu dois anos posteriores. (Stiglitz, 2003, pp. 66-67)

Comparativamente, o governo de Bush I foi o que apresentou a pior performance entre os anos 1980 e 2000. A taxa média de crescimento do produto foi de 
$2,12 \%$ a.a. entre 1989 e 2000, ante uma taxa média de 3,4\% do período Reagan ${ }^{5}$ e $3,7 \%$ da administração Clinton. Vale lembrar que a taxa do primeiro ano governo Bush I ainda representa um nível elevado (3,5\%), não captando a desaceleração que viria a se confirmar nos dois anos seguintes. A taxa de desemprego sairia de 5,3\% da população economicamente ativa em 1989 para 7,5\% em 1992 (último ano do mandato).

Em boa medida coube ao governo de Bush I fazer os ajustes, que seriam decisivos para a eleição do governo democrata de Clinton.

O governo democrata marca o período da afirmação da hegemonia americana, cuja retomada fora construída desde o final do governo Carter, com os choques de juros de Volcker, e do governo Reagan, a partir da política do dólar forte e de uma política externa agressiva no campo militar e econômico. Nesse aspecto, não há uma solução de continuidade entre os governos republicano e democrata, contudo, seria incorreto afirmar que as políticas públicas, macroeconômicas e as características da política externa de modo geral foram as mesmas em todos esses governos.

Os governos republicanos estiveram na base do processo de emergência de uma visão de mundo marcadamente triunfalista e com conteúdo conservador no campo político e liberal no campo econômico. O governo democrata seria uma suavização dessa perspectiva, mas de modo algum sua negação definitiva. No campo econômico, ao menos no tocante aos princípios fundamentais da liberalização comercial, produtiva e financeira, ele representará uma continuidade dos governos anteriores.

O tratamento dado aos processos críticos de falta de liquidez no plano externo durante o governo Clinton diferiram do governo Reagan; em outras palavras, a crise que viria a partir da segunda metade dos anos 1990 recebeu um tratamento diferenciado daquele dispensado à América Latina nos anos 1980, depois do default mexicano de 1982. Isso não é irrelevante, ao contrário, mostra que a experiência dos anos 1980 fora parcialmente apreendida. De toda forma, a mudança de postura não elimina o fato de que as raízes que levaram à crise financeira dos anos 1990, não foram eliminadas pelo governo democrata, ao contrário, foram por ele animadas, por conta da continuidade que a administração Clinton representou no processo de expansão das finanças desregulamentadas. Saliente-se também que nesse período os problemas de coordenação e a tomada de decisão no plano estatal ficaram mais complexos por conta da pulverização dos atores envolvidos nos mercados financeiros internacionalizados e da estrutura de suas carteiras. Não se tratava, apenas, de grandes bancos operando offshore, mas de atores financeiros institucionais (fundos de investimentos de diferentes tipos) que expunham governo e famílias por meio da internacionalização de suas carteiras. Uma deflação generalizada de ativos implicava grave risco para a renda dos cidadãos estadunidenses.

\footnotetext{
${ }^{5} \mathrm{O}$ governo Reagan assume em meio à recessão, sendo que somente a partir do terceiro ano é que a economia entra numa rota consistente de crescimento.
} 
Em boa medida a agenda financeira ganha força no governo Clinton a partir de sua incapacidade de levar adiante sua agenda interna, a qual representaria o divisor de águas com os governos republicanos. Cabe lembrar que, após um ano de poder, a administração democrata perderia a maioria no Congresso para o partido republicano.

In the case of the Clinton administration, although the president and his staff wanted to focus on health care, welfare, public investment, education, and the information superhighway, in its first two years the Clinton White House failed to win the support of a divided Senate for major domestic initiatives other than the 1993 Clinton-Mitchell-Foley deficit-reduction package. And following the loss of Democratic control of the Congress in 1994, all ambitious domestic iniatives were obviously dead in the water. If this didn't exactly create a political vacuum and a demand for newspaper headlines that could only be filled by international events, it at least facilitated the efforts of Treasury and other economic agencies to bring these issues to attention of the president and his core political advisors. (Eichengreen e Delong, 2001, p. 2)

A dinâmica política interna conduz o governo cada vez mais para a proximidade dos grupos de interesse ligados ao Tesouro e a Wall Street. Cumpre destacar que o secretário do Tesouro americano, durante boa parte dos dois mandatos do governo Clinton, foi Robert Rubin, cuja trajetória profissional fora construída em boa medida no setor financeiro privado ${ }^{6}$.

Nesse contexto a estratégia do crescimento interno passa a ser função da conquista dos mercados externos. A expansão do capital americano para o mercado mundial dependia da combinação de um quadro interno com baixas taxas de juros e de um cenário internacional propício, do ponto de vista normativo, para a internacionalização dos negócios.

Para redução das taxas de juros era necessária uma redução significativa do déficit público, algo que foi perseguido, com sucesso, pelo governo. A manutenção de juros baixos também facilitava a expansão da liquidez internacional. A diplomacia americana operaria de forma intensiva para a abertura dos mercados, cumprindo papel de destaque as Instituições Financeiras Multilaterais (FMI e World Bank).

Pensava-se que a abertura comercial atacaria o problema da balança comercial, a produtiva geraria novos espaços de valorização para o capital americano e a financeira produziria a afirmação do dólar no contexto da expansão dos serviços financeiros, o que facilitava o financiamento da conta de transações correntes.

\footnotetext{
${ }^{6}$ Trabalhou durante 26 anos na Goldman Sachas \& Co. Saiu do mercado financeiro para trabalhar com o governo Clinton, tendo inicialmente assumido a presidência do National Economic Council (conselho criado durante a administração Clinton) e posteriormente a Secretaria do Tesouro. Rubin teve como subsecretario do Tesouro Lawrence Summers, que depois iria se tornar secretário do Tesouro nos dois últimos anos da administração Clinton.
} 
Aspecto fundamental cumpria a abertura das contas de capital. Isso estava em plena concordância com o cenário que vinha se construindo desde a crise de Bretoon Woods.

The administration's support account liberalization flowed naturally from its belief in free and open markets. As Rubin put it in a speech timed to coincide with the Spring 1999 Bank-Fund meetings, "Our approach [...] has been informed by the fundamental belief that a market-based system provides the best prospect for creating jobs, spurring economic activity, and raising living standards in the U.S. and around the world.” It was a function of the belief that controls on capital flows created opportunities for corruption. It reflected the view that domestic financial liberalization had profoundly important benefits, but also the side effect of rendering capital controls that much more difficult and distortionary to administer and operate. (Eichengreen, 2001, p. 62)

O contexto político dos anos 1990 foi extremamente favorável para essa estratégia. Enquanto a economia americana crescia de forma exuberante, recuperada da recessão do início da década, o poder americano no mundo parecia incontrastável. O efeito demonstração dos benefícios do "livre mercado" para o sucesso da maior economia capitalista alimentava ideologicamente o processo de liberalização mundo afora. $\mathrm{Na}$ América Latina isso representava a promessa de recuperação após a crise dos anos 1980 e para o Leste Asiático a abertura era fortemente associada com a possibilidade de expansão dos fluxos de comércio. O Leste Europeu encontrava-se sem rumo, após a derrocada do socialismo real e tornara-se presa fácil das reformas liberalizantes.

Os perigos associados à liberalização prematura das contas de capital eram subestimados diante das promessas das recompensas para se atingir níveis de classificação de risco em conformidade com as exigências dos mercados. Uma equação simples: redução das ineficiências do mercado provocadas pelas interferências estatais levariam os países a um maior acesso ao imenso fluxo de capitais que se criara com a internacionalização dos mercados.

Nos EUA as críticas dentro da administração democrata ${ }^{7}$ foram enfraquecendo à medida que a estratégia do Tesouro mostrava resultados concretos em termos de crescimento e equacionamento da dívida pública interna. Isso aumentou o poder de pressão de Wall Street e seus aliados dentro do governo para uma ação ativa em prol da liberalização das contas de capital dos países periféricos. As subsequentes crises cambiais e financeiras que ocorreram a partir de 1995 não refrearam o ímpeto liberalizante e desregulacionista.

Em boa medida as crises não levaram a alterações no sistema financeiro inter-

\footnotetext{
${ }^{7}$ Uma descrição a respeito do debate dentro da área econômica do governo Clinton pode ser verificada em Stiglitz, (2002).
} 
nacional, leia-se no regime monetário, porque não atingiram o centro dinâmico da acumulação. Alterações de caráter estrutural não ocorrem sem que haja mudanças que afetem os principais atores do sistema. Além disso:

O sistema financeiro internacional é uma rede muito densa de instituições sociais, econômicas e financeiras. Como acontece com qualquer mecanismo complexo, há limites para que mudanças de um único componente sozinho sejam por si sós factíveis enquanto os demais permanecem como estão. [...] O resultado é que o sistema evolui gradualmente através de remendos na margem [...]. Não devemos nos surpreender quando mesmo desarranjos severos, como a crise asiática, não chegam a provocar mudanças radicais nas instituições e arranjos existentes, ainda que possam dar um impulso adicional a mudanças já em curso.” (Eichengreen, 2003, p. 2)

As características fundamentais do sistema financeiro internacional em vigor foram construídas dentro de um período relativamente longo, mas que em grande medida refletiram os interesses de instituições sociais, econômicas e financeiras que foram sendo moldadas a partir do exercício hegemônico norte-americano. A sua formação obedece a padrões de financiamento e transformação da riqueza que operam sob a lógica dos mercados desregulamentados e que contam com um amplo conjunto de interesses que foram se enraizando nos aparatos normativos e nas legislações de diferentes países e instituições internacionais. As forças institucionais dão o suporte social para a forma de apropriação da riqueza no capitalismo contemporâneo e a expansão dessa lógica resulta na reprodução das assimetrias de poder dentro do sistema de Estados. Há um movimento de expansão do capital que integra mercados e captura parte das políticas soberanas às necessidades da grande potência.

Esse processo de globalização e dominância financeira pressupõe a internacionalização e a liberdade dos movimentos de capitais, porém envolve um movimento adicional, qual seja, a integração dos mercados financeiros e de capitais domésticos offshore. Exige, portanto, a aproximação entre a legislação e a regulamentação das instituições e normas domésticas. [...] A marca distintiva do atual movimento de internacionalização capitalista é a forma em que se deu a globalização das finanças, viabilizada pelas políticas de desregulamentação dos mercados, iniciada pelos EUA e alavancada pelo sistema de taxas de câmbio flutuante. As finanças passaram a operar num "espaço mundial", hierarquizado a partir do sistema financeiro americano e viabilizado pela política monetária do Estado hegemônico, imitadas, de imediato, pelos demais países industrializados. (Braga e Cintra, 2004, pp. 266-267)

Esse movimento, porém, não nos deve levar a supor que todas as resultantes sempre operem no sentido dos interesses do Estado hegemônico. Primeiro é preci- 
so pensar que as ações nem sempre levam a resultados desejados; segundo, não há como ter um controle prévio dos resultados num sistema que opera de forma competitiva, mesmo que essa competição seja assimétrica; terceiro, os atores políticos, as forças sociais e as instituições não agem de forma puramente racional ou simplesmente adaptativa.

Em relação ao primeiro aspecto cabe destacar que as mesmas forças que promovem a abertura possibilitam a entrada de novos competidores, alterando os ganhos recíprocos e a estrutura dos mercados. Assim, embora haja uma circularidade baixa da hierarquia no sistema de estados, novos entrantes de tempos em tempos alteram a distribuição da riqueza e os custos relativos dos fatores de produção. A expansão asiática recente mostra alterações importantes na divisão internacional do trabalho, cujos resultados ainda são incertos, mas que desde já afetam as relações entre compradores e vendedores, bem como, talvez mais importante, entre credores e devedores no plano internacional.

Em relação ao segundo aspecto, é da natureza do capitalismo a existência de um processo de valorização do capital que gera descompassos entre a produção e o consumo, entre pagamentos e recebimentos. O padrão de valorização capitaneado pela esfera financeira tem dado demonstrações seguidas de instabilidade, por meio de sucessivos movimentos de inflação e deflação de ativos, o que gera tensões permanentes e afeta as decisões estratégicas dos atores, aumentando o grau de risco sistêmico.

Por último, o aumento do grau de risco e incerteza limita a previsibilidade das ações e acirra conflitos, alterando as alianças dentro do sistema de Estados. Não se pode esperar que as ações dos atores sejam totalmente racionais ou simplesmente adaptativas.

Nesse contexto, os limites da ação hegemônica parecem ter assumido novas proporções desde o fim do governo Clinton e o desenrolar dos dois mandatos republicanos de George Bush II.

A mudança de governo, que representa o fim da exuberante trajetória dos anos 1990, também representará uma série de desafios para a liderança americana. A trajetória de crescimento trazia um saldo de ressentimentos originados pela crise asiática, pelas promessas não cumpridas da globalização e pelo descontentamento crescente com o unilateralismo americano. O que fora um período de grande sucesso para a economia americana, representara um ciclo de desenvolvimento desigual para a economia mundial. Parte expressiva dos países que abraçaram as estratégias market friendly dos anos dourados da globalização sentiam o peso de anos de crescimento medíocre, de desequilíbrios financeiros e cambiais graves e de desajustes importantes em termos de emprego. Em contraste, a China, que ousara desenvolver uma estratégia própria de desenvolvimento ("um país, dois sistemas"), abrindo-se para a competição externa, mas mantendo controles sobre a determinação de preços-chave na economia, dentre os quais câmbio e juros, apresentava um desempenho impressionante em termos de crescimento do produto, atração de capitais e formação de reservas.

A globalização criava, dessa forma, variáveis que saíam ao controle da super- 
potência. Pouco a pouco o padrão de valorização sob o domínio financeiro apresentava sinais de esgotamento, pouco a pouco a supremacia e a liderança americana diminuíam seu ímpeto. As ações bélicas do novo governo republicano demonstrariam a clara perda da liderança americana, do acirramento da disputa por recursos escassos, num mundo em crescente competição, e dos limites que o poder americano enfrentaria. Aqui, tratamos de pensar o poder em termos de hegemonia, da capacidade de liderança que deve ser exercida sem que se necessite do uso da força (pensamos na tradição crítica de Robert Cox, que afirma a pertinência da perspectiva gramsciana na análise internacional (Cox, 1999; Velasco e Cruz, 2000).

No plano interno a economia americana mostrava sinais de fraqueza, combinando perda de dinamismo e desconfiança em relação ao poder americano, principalmente depois dos atentados de 11 de setembro de 2001.

Após atingir um impressionante crescimento médio de 4,3\% entre 1997 e 1999, a economia americana começa sua trajetória de queda. O período das empresas "ponto com", da nova economia, que prometia o fim dos ciclos econômicos, chegava ao fim. O período dos "Novos Democratas" 8 mostrava sua fraqueza, cedendo espaço para a ascensão do neoconservadorismo e da política do big stick.

\section{AS DESVENTURAS DOS BEM-AVENTURADOS}

O primeiro ano do governo Bush II seria uma combinação de recessão com crise política. Um governo que assumia com um discurso imperalista, de destino manifesto, alicerçado numa estratégia de domínio explicita (hard power). Os gastos com a defesa nacional que decresceram sistematicamente durante o governo Clinton, aumentaram dramaticamente com o novo governo, demonstrando uma clara recomposição dos interesses do complexo militar industrial ${ }^{9}$. Paralelamente ao aumento dos gastos militares o novo governo, comprometido com a trajetória republicana de corte de impostos, diminuía as fontes de receitas, revertendo o quadro fiscal positivo que fora construído durante o governo Clinton.

Para reverter a recessão de 2001, o governo reduzira impostos e diminuíra as taxas de juros. Esses fatores, combinados com uma regulação frouxa, seriam suficientes para a expansão dos negócios imobiliários, cuja bolha resultaria em 2008

\footnotetext{
8 "Por doze anos, durante os governos Reagan e Bush I, a política econômica nacional foi formulada por ideólogos do mercado livre que idealizavam o setor privado e crucificavam os programas e as regulamentações governamentais. Bill Clinton, como muitos que atuaram em sua administração, identificou-se com a chamada Nova Democracia - um grupo desconexo de políticos, acadêmicos e sabichões formuladores de políticas que achavam que o Partido Democrata, no passado, estivera muito propenso a soluções burocráticas e despreocupado demais com o impacto de suas políticas sobre os negócios e o mercado" (Stiglitz, 2003).

${ }^{9}$ Durante os primeiros quatro anos do mandato republicano, as taxas médias de crescimento anual com os gastos nacionais de defesa foram: 3,9\% (2001), 7,4\% (2002), 8,7\% (2003) e 5,8\% (2004). (dados extraídos do Bureau of Economic Analysis - www.bea.gov).
} 
na maior crise financeira do pós-segunda Guerra e que levaria à eleição de Barack Obama para a presidência. A taxa básica dos Federal Funds cairia de 6,24\% em 2000 para $1,13 \%$ em 2003. A prime rate, utilizada em muitos contratos imobiliários, sairia de um patamar de 9,23\% em 2000 para 4,12\% em 2003.

As aventuras do campo militar e as desventuras da perda relativa do dinamismo econômico fizeram do governo Bush um período diametralmente oposto daquele verificado no período democrata anterior, mas é importante destacar que muitas das políticas externas relacionadas ao campo econômico permaneceram bem próximas dos governos americanos dos anos 1980 e 1990.

“[...], actual policies differed less from those of earlier presidents than the administration's rhetoric would have led one to suppose. Where political scientists and diplomatic historians are apt to see the Bush presidency as a distinctive epoch in American foreign policy, we argue that there was no Bush Doctrine in international economic policy. [...] This leads us to expect there will be continuities with future policy as well. Neither the new foreign policy concerns created by $9 / 11$ nor long-standing structural constraints on international economic policy making will go away. (Eichengreen e Irwin, 2007, pp. 2-3)

Vários dos constrangimentos e oportunidades do quadro econômico internacional permanecem na agenda americana. Em especial a crescente necessidade de financiamento da economia dos EUA, em função do déficit em transações correntes e do déficit interno, o que nos leva a supor que será difícil uma postura diferente daquelas adotadas até aqui no sentido de uma reforma do sistema financeiro internacional e de alterações no padrão monetário. A liberdade do movimento de capital e o papel do dólar no espaço internacional são de vital importância para a economia e o poder americanos.

\section{CONCLUSÕES (CRISE, HEGEMONIA E TRANSIÇÃO)}

Os ventos da incerteza assolaram a economia e o poder mundial em setembro de 2008. A primeira década do século XXI assistiu a dois grandes eventos que afetaram o quadro das relações de poder no sistema internacional. São eventos de ordens distintas, embora, de alguma forma, reflitam algo similar: as inconsistências da hegemonia estadunidense no interior do sistema de Estados. O primeiro, veio de fora, com aviões sendo despejados sobre a capital do capital: Nova york. O segundo veio de dentro, com o derretimento dos preços dos ativos financeiros e a subsequente crise de crédito $^{10}$. Ambos denotam a incapacidade de gestão de uma

\footnotetext{
${ }^{10}$ Para um detalhamento dos aspectos econômicos da crise financeira ver Vidotto (2008); Freitas e Cintra (2008).
} 
ordem onde a primazia, se não a exclusividade, das tomadas de decisões relevantes se concentraram numa única grande potência. Os eventos explicitam também a instabilidade de uma forma de organização de poder com características unipolares. Se olharmos para os anos 1990 e compararmos com os anos 2010, veremos quão contrastantes são as imagens. Naqueles, o poder econômico e militar estadunidense configurava uma percepção de uma ordem que caminhava para um império. Nesses, a grande potência mundial parece derreter junto com a superacumulação de responsabilidades geoestratégicas e com a queima generalizada dos ativos.

Qual é o impacto da crise financeira atual sobre o poder americano? Essa é uma crise financeira de caráter conjuntural, ou a expressão de alterações nas estruturas do sistema de Estados? Creio que não podemos ver esse período como sendo apenas um ajuste severo nos preços dos ativos, como uma falha de mercado que será corrigida por um novo equilíbrio, como uma manifestação conjuntural de problemas funcionais do sistema financeiro, pois bem, como uma correção conjuntural. A crise atual não é apenas a causa do que virá, mas a expressão de mudanças importantes na estrutura de funcionamento do sistema de Estados. Embora esta estrutura ainda continue a ser dominada pelo seu ator principal, o Estado Nacional, a balança de poder está se alterando e cabe-nos verificar e interpretar os sinais que apontam nessa direção.

Ela é uma crise do regime de legitimidade ${ }^{11}$, com impactos importantes nas relações interestatais. Ela é o crepúsculo de um movimento de desregulamentação que teve em sua origem a crise do sistema de Bretton Woods em 1971 e que subordinou as decisões de políticas soberanas ao movimento de expansão do capital, em especial à dominação financeira. O abalo sísmico provocado pelo deslocamento da dinâmica da acumulação e pelos arranjos institucionais da alta finança revela um ambiente de alterações profundas na divisão internacional do trabalho e abre um universo dinâmico de novas articulações e composições de interesses geoestratégi$\cos$ (nas suas dimensões política e econômica).

Vale lembrar: um aspecto central do poder americano está no domínio sobre o padrão monetário internacional. Tanto o regime financeiro internacional quanto o padrão monetário estão deixando a desejar em três requisitos fundamentais: capacidade de ajustamento, liquidez e a existência de um emprestador de última instância (estabilidade). Isso enfraquece a liderança americana porque mina progressivamente a eficácia dos instrumentos que dispõe para conciliar seus interesses com uma ordem internacional estável.

I suggest that the current international balance of power represents a case of gradually declining U.S. dominance, and consequently a situation of rising global multipolarity. If the theory of hegemonic stability

\footnotetext{
${ }^{11}$ Por regime entendem-se as normas que orientam as ações dos atores e sujeitos de direito. "A legitimidade poderia ser objeto de uma definição geral, finalmente simples em sua expressão literal: é o poder efetivo ou potencial que têm as autoridades públicas para manter a ordem estabelecida sem exercer continuamente a coerção pública em larga escala” (Dehove, 1998, pp. 150-151).
} 
is valid, then designing and managing an effective international financial architecture for the twenty-first century therefore will be a more difficult task than constructing and maintaining the Bretton Woods regime was. (Armijo, 2002, p. 33)

A crise atual mina o consenso construído nas últimas décadas e mais ainda, mina a autoridade moral da nação que abriu o caminho para o livre movimento dos capitais.

The shocks of the past year another thirty years on from the last major shift support the conjecture that we are witnessing a third regime change, propelled by a wholesale loss of confidence in the AngloAmerican model of transactions-oriented capitalism and the neoliberal economics that legitimized it (and by the US'S loss of moral authority, now at rock bottom in much of the world). Governmental responses to the crisis further suggest that we have entered the second leg of Polanyi's "double movement", the recurrent pattern in capitalism whereby (to oversimplify) a regime of free markets and increasing commodification generates such suffering and displacement as to prompt attempts to impose closer regulation of markets and de-commodification (hence 'embedded liberalism). The first leg of the current double movement was the long reign of neoliberalism and its globalization consensus. The second as yet has no name, and may turn out to be a period marked more by a lack of agreement than any new consensus. (Wade, 2008, pp. 6-7).

Os EUA são uma nação devedora (verificar anexos) e isso é um sintoma de que sua capacidade de liderança no sistema de Estados está se tornando menor. Toda nação devedora é por definição vulnerável e sensível às alterações cíclicas, sendo que vulnerabilidade e sensibilidade guardam uma relação inversa à autonomia, que é em boa medida a representação do poder. Quando o grau de autonomia diminui, por consequência diminui o poder e aumentam os custos das alternativas em situações de risco ${ }^{12}$.

America's continuing large current account deficit and ongoing dependence on foreign central banks for finance will continue to be a source of vulnerability going forward. The fact critical finance is provided by the central banks and governments of countries like China and Saudi Arabia means that anything that upsets U.S. relations with these countries could upset the U.S. economy as well. In turn this gives foreign governments a lever with to demonstrate their displeasure with U.S. foreign policy. [...] More generally, the country's external deficit and dependence

\footnotetext{
${ }^{12}$ Ver nesse sentido "Currency and State Power" (Cohen, 2009).
} 
on foreign finance heightens economic risks. One can equally imagine that foreign central banks, seeing the U.S. external deficit as unsustainable, might shift out of dollars in order to avoid capital losses on their reserve portfolios. In the longer run a chronically weak dollar will encourage foreign central banks, governments and corporations to consider alternatives to the dollar as the medium in which to hold reserves, price petroleum, invoice trade etc. Estimates of the value to the United States of the dollar's international currency status varies, but the country clearly will be no better off when that status is history. (Eichengreen e Irwin, 2007, pp. 27-28)

É razoável levar em consideração que a economia americana é a maior economia do planeta e que quedas acentuadas de sua demanda efetiva provocam efeitos negativos para o conjunto da economia mundial; também devemos levar em consideração que o padrão monetário internacional ainda é o dólar e que os países que detêm reservas nesse ativo monetário não têm interesse imediato de que ele venha a perder valor, seja porque uma desvalorização contínua do dólar diminui a riqueza dos que o carregam em sua carteira (ou como reserva), seja porque os credores que tem seus contratos denominados em dólar também perdem riqueza. A desvalorização beneficia quem carrega seus passivos em dólar e emite essa moeda, ou seja, os Estados Unidos.

Por sua vez os credores (os detentores da riqueza líquida) não podem simplesmente negar liquidez ao sistema ou deixar de atuar como emprestadores de última instância para o Estado emissor, em momento de escassez de recursos ou de crise de pagamentos, mas isso gera um paradoxo, qual seja, o emprestador de última instância, o emissor (EUA), precisa enxugar liquidez internacional em função de sua necessidade de ajustamento, o que corrói o regime de legitimidade. As necessidades de ajustamento da nação emissora levantam questionamentos sobre a arquitetura financeira internacional e sobre a relação entre o poder estatal e a moeda de circulação internacional. Nesse aspecto é preciso integrar a análise econômica à política, para que não caiamos na armadilha de uma análise estrutural que tem a capacidade de descrever a estabilidade e a estrutura e não consegue pensar sobre os sintomas da mudança.

Essa situação foi provocada por um processo contínuo de expansão dos mercados e pela criação de fluxos cruzados comerciais, financeiros e tecnológicos que acompanharam a expansão do regime de acumulação nos últimos trinta anos. $\mathrm{O}$ capital, na sua dimensão financeira, provocou uma intensa interligação dos mercados, afetando o modo de ser e de se expressar da riqueza. As relações econômicas que surgiram, criaram relações interdependentes, em larga escala, e problemas que surjam no modus operandi do sistema afetam o conjunto das nacionalidades.

Num sistema com alto grau de interdependência como o atual, as ações individuais devem levar em consideração os movimentos de reação ou as externalidades e retornos que os atos individuais produzem. Estamos diante de um problema de ação coletiva. Os incentivos para mudar o padrão monetário são inúmeros, mas diante 
da ausência de um substituto perfeito os custos são imprevisíveis, o que aumenta as sombras da incerteza sobre o presente e limita a ação dos atores. Cabe ressaltar que enquanto o dólar for a expressão de um poder descendente, os incentivos levarão à busca de substituição. Isso nos leva a crer que esse processo já está em curso, mas seu desfecho é ainda imprevisível, posto que a moeda é uma função de expectativas e a função expectativa, nesse caso, depende da percepção dos agentes relativamente ao poder do Estado emissor e da capacidade de outros Estados, candidatos à posição de potência líder, em dar as garantias necessárias para uma ordem estável.

As funções da moeda, no plano internacional, não se diferenciam muito das funções da moeda no plano nacional, portanto, o padrão monetário para se impor precisa cumprir os requisitos de unidade de conta, meio de pagamento e reserva de valor. Uma alta volatilidade no preço do equivalente internacional corrompe as suas funções. O dólar vem cumprindo de maneira muito imperfeita essas funções porque a nação emissora vive com déficits crônicos, é um Estado devedor, e mais importante, porque há uma percepção generalizada de que os EUA estão perdendo sua primazia no sistema de Estados. As pressões no sentido de alteração de voto e reformulação do poder relativo do atores soberanos nos fóruns internacionais e nas instituições internacionais têm sido uma constante. Soluções $a d$ hoc por parte dos Estados Unidos estão sendo cada vez mais colocadas em questão. A diminuição da primazia não pode ser entendida como a simples substituição de uma hegemonia por outra, mas como uma abertura de um período de transição, que tudo indica nos leva para uma ordem multipolar.

A hegemonia americana se consolidou pela transformação dos mesmos numa nação credora. $\mathrm{Na}$ base desse processo esteve a expansão econômica interna e a capacidade de expandir seus negócios offshore, mas é a partir de sua transformação em nação credora que o padrão monetário baseado no dólar se difundiu. O ciclo de expansão e consolidação do dólar como padrão universal durou cerca de 85 anos, o que corresponde ao início dos anos 1920 até o século XXI. Desde os anos 1970 esse padrão sofreu abalos, mas não havia uma transformação importante o suficiente na distribuição dos recursos internacionais que viesse a corresponder a uma ameaça efetiva ao domínio do dólar. Esse processo começou a se alterar com o deslocamento da dinâmica da acumulação para o continente asiático, cerca de 28 anos atrás. Essa transformação trouxe para a arena internacional uma massa expressiva de consumidores e uma máquina de produção em larga escala, a China. Alterações dessa natureza alteram os preços relativos dos fatores e a alocação de recursos; alteram, portanto, a divisão internacional do trabalho.

Essas alterações estruturais produziram efeitos visíveis no plano geoestratégico. As investidas militares dos Estados Unidos na Ásia Central, bem como no Oriente Médio, são manifestações de ações preventivas tomadas na disputa por recursos escassos, bem como pelo posicionamento estratégico por meio de tomada de posições no tabuleiro dos movimentos espaciais. $\mathrm{O}$ problema que surge numa situação como essa é a hipertrofia de funções e atribuições, aumentando os custos de reprodução da hegemonia. A crise financeira ocorre no contexto de questionamento crescente do poder americano. Espasmos financeiros são parte do ciclo 
econômico, mas crises financeiras sistêmicas têm efeitos sistêmicos e provavelmente são resultado de problemas estruturais que transcendem o campo econômico.

Hipertrofia e excesso, características expressivas dos problemas americanos. A hipertrofia conduz a um conjunto de demandas em termos políticos e econômicos que não são satisfeitas, ou são apenas parcialmente satisfeitas. Para suprir esse déficit de capacidade, o poder hipertrofiado é forçado a ceder parte de suas atribuições e a sacrificar interesses, caso contrário o sistema tende a um acirramento dos conflitos e a disfuncionalidades. A economia americana acostumou-se ao excesso, ao superconsumo, ao superendividamento. Disso resultam desequilíbrios internos e externos (conforme dados que se encontram nos anexos). Os ajustes provocados pelos desequilíbrios das contas americanas podem levar ao acirramento dos conflitos de interesse dentro da sociedade americana, diminuindo a capacidade do Estado americano em lidar com o conjunto competitivo e complexo de interesses que disputam o espaço estatal ${ }^{13}$.

Um dos aspectos fundamentais dos tempos de incerteza e transição é o aumento do acirramento dos conflitos, mas também a possibilidade de novos arranjos institucionais (Keohane, 1988). O presente artigo buscou demonstrar que um elemento fundamental de continuidade da política externa americana nas últimas três décadas foi o compromisso com uma arquitetura financeira internacional baseada no livre fluxo de capitais e num regime monetário que garantisse a supremacia dos EUA por meio dos laços entre a moeda e o poder estatal, relação esta que permitiu um grau mais elevado de autonomia e maior capacidade dessa nação em influenciar os resultados dos jogos de interesse dentro do sistema de Estados. A crise financeira e econômica que se instalou a partir de 2008 evidencia os custos desse regime e provoca uma nova rodada de discussões sobre a arquitetura financeira internacional. Essa discussão, como tentamos salientar, envolve muito mais que os aspectos instrumentais de um sistema financeiro internacional mais ou menos eficiente. Para entendermos quais os rumos dessa discussão será importante verificar em que medida o grau de autonomia americana vem sendo afetado pela alteração na dinâmica espacial da acumulação, pela ascensão de novos atores soberanos e pela crise econômica recente. Para aqueles que se preocupam com a importância dos eventos externos, caberá verificar quais os movimentos que irão ocorrer em termos de distribuição de capacidades, alterações institucionais e de formação de alianças. Do ponto de vista da análise do poder externo estadunidense, a era Bush deixou um legado de utilização contínua e em larga escala da coerção, o que em termos dedutivos é uma representação da perda de poder. Se compararmos os anos $1990 \mathrm{com}$ a primeira década do século que se inicia, poderíamos afirmar que os anos 1990 criaram o mito da supremacia americana (unipolaridade) e a primeira década do

\footnotetext{
${ }^{13}$ O governo democrata de Barack Obama, nos seus primeiros momentos, está diante da tentativa de recolocar na ordem do dia a agenda democrata, nunca cumprida, da reforma da saúde, bem como da reforma do sistema financeiro, ambas aprovadas pelo Congresso americano no primeiro semestre de 2010.
} 
presente milênio colocou-a em questão. Nesse aspecto vale lembrar a perspectiva gramsciana da análise das relações internacionais, de que ideias, instituições e capacidades materiais são três elementos que se combinam para o exercício da hegemonia. Em geral alterações na distribuição das capacidades materiais tendem a afetar tanto a visão de mundo dominante como o funcionamento das instituições, porquanto das regras que regulam as relações entre os atores relevantes do sistema de estados. O presente contexto nos mostra que estão abertas as possibilidades de reformas nas instituições internacionais, com destaque para o fato de que há uma combinação entre alterações no quadro de referências na tomada de decisão dos atores, bem como na distribuição das capacidades materiais, com ênfase na dimensão econômica destas últimas.

\section{REFERÊNCIAS BIBLIOGRÁFICAS}

ARMIJO, Leslie E. (2002) Debating the Global Financial Architecture. New York: State University of New York Press.

AXELROD, Robert e Roberto O. KEOHANE (1985) “Achieving cooperation under anarchy: strategies and institutions. World Politics, 38 (1), p. 226-254.

BELUZZO, Luis G. (1997) "Dinheiro e as transfigurações da riqueza”. In Tavares, Maria C.; Fiori, José L. (org.). Poder e Dinheiro: Uma Economia Politica da Globalização. Petrópolis, RJ: Vozes, p. 151.

BRAGA, José C. (1997) "Financeirização global - O padrão sistêmico de riqueza do capitalismo contemporâneo". In Tavares, Maria C.; Fiori, José L. (org.). Poder e Dinheiro: Uma Economia Política da Globalização. Petrópolis, RJ: Vozes, p. 195.

BRAGA, José C. S. e Marcos A. M. CINTRA (2004) "Finanças dolarizadas e capital financeiro: exasperação sob comando americano”. In Fiori, José L. (org.). O Poder Americano. Petrópolis, RJ: Vozes, p. 266-267.

COHEN, Benjamin (2008) International Political Economy: an intelectual history. Princeton: Princeton University Press

COHEN, Benjamin (2009) "Currency and State Power. Santa Barbara, US. Disponível em: <www. bjcohen.ucsb.edu/cohen>. November.

COX, Robert (1999) "Social forces, States, and world orders: beyond international relatios theory (1981)". In Cox, Robert W. e Sinclair, Timothy J. (orgs.). Aproaches to World Order. Cambridge: Cambridge University Press, p. 60-85.

DEHOVE, Mario (1998) “Elementos sobre a gênese das organizações internacionais”. In Théret, Bruno e Braga, José Carlos de Souza. Regulação Econômica e Globalização. Campinas, SP: Unicamp, p.121-185.

EICHENGREEN, Barry (2003) Crises Financeiras: Análise, Prevenção e Gestão. Rio de Janeiro: Campus. EICHENGREEN, Barry e J. Bradford DELONG (2001) Between Meltdown and Moral Hazard: The International Monetary and Financial Policies of the Clinton Administration. University of California at Berkley and NBER.

EICHENGREEN, Barry e Douglas A. IRWIN (2007) The Bush Legacy for America's International Economic Policy. Disponível em: <http://www.econ.berkeley.edu/ eichengr/bush_legacy.pdf >. Acesso em: 28 junho 2008.

FREITAS, Maria C. P. e Marcos A. M. CINTRA (2008) E la nave va: inflação e deflação de ativos. Disponível em: <http://www.sep.org.br/artigo/3_congresso/1177_252212f35d24ae98dd7f30bd8 d8e5f3c.pdf>. Acesso em: 15 abril 2008.

GILPIN, Robert (1999). War and Change in World Politics. Cambridge: Cambridge University Press.

KEOHANE, Robert O. (1988) Despues de la Hegemonia. Cooperación y Discórdia en la Politica Econômica Mundial. Buenos Aires: Grupo Editor Latinoamericano S.R.I. 
MINSKY, Hyman P. (1994) “Integração financeira e política monetária”, Economia e Sociedade. Universidade Estadual de Campinas (Unicamp), Instituto de Economia, n. 3, dezembro.

MIRANDA, José C. (1997) "Dinâmica financeira e política macroeconômica”. In: Tavares, Maria C.; Fiori, José L. (org.). Poder e Dinheiro: Uma Economia Política da Globalização. Petrópolis, RJ: Vozes, p. 243.

PRATES, Daniela M. e Marcos A. M. CINTRA (2008) "Keynes e a hierarquia de moedas: possíveis lições para o Brasil”. In Sicsú, J. e Vidotto, Carlos (org.) Economia do Desenvolvimento: Teoria e Políticas Keynesianas. Rio de Janeiro: Elsevier, p. 175-199.

SERRANO, F. (2004) "Relações de poder e a política macroeconômica americana, de Bretton Woods ao padrão dólar flexível”. In Fiori, José L. (org.). O Poder Americano. Petrópolis, RJ: Vozes, p. 179.

STIGLITZ, J. (2002) A Globalização e seus Malefícios: A promessa não cumprida de benefícios globais. São Paulo: Editora Futura.

STIGLITZ, J. (2003) Os Exuberantes Anos 90: Uma Nova Interpretação da Década Mais Próspera da História. São Paulo: Companhia das Letras.

VELASCO E CRUZ, Sebastião C. (2002) "Um outro olhar: sobre a análise gramsciana nas relações internacionais" Revista Brasileira de Ciências Sociais 15 (42), p. $39 .$.

VIDOTTO, Carlos (2008) "O espectro de Keynes ronda a América: hipotecas, securitização e crise financeira nos Estados Unidos”. In Sicsú, João; Vidotto, Carlos (org.). Economia do desenvolvimento. Rio de Janeiro: Elsevier.

TAVARES, Maria da Conceição (1997). “A retomada da hegemonia americana”. In Tavares, Maria da Conceição e Fiori, J. Luís (org.). Poder e Dinheiro - Uma Economia Política da Globalização. Petrópolis, RJ: Vozes.

WADE, R. (2008) “Financial regime change?” New Left Review, September-October..

\section{GRÁFICOS}

Gráfico 1: Variação Percentual em Relação ao Período Anterior do PIB Real

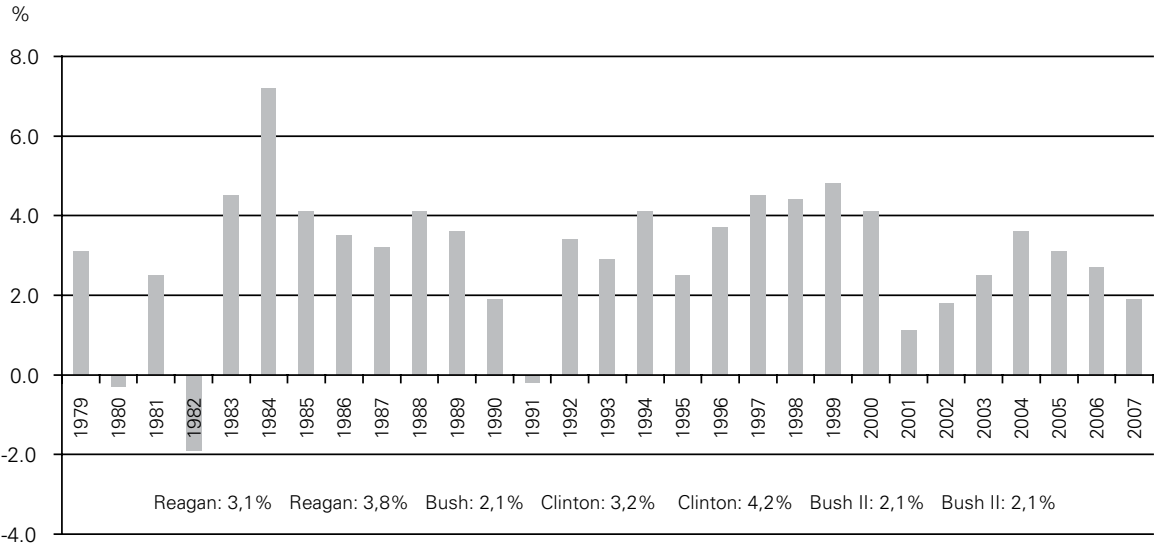

Fonte: U.S. Department of Commerce. Bureau Of Economic Analysis

Elaboração: Núcleo de Economia e Política Externa 
Gráfico 2:

Principais Taxas de Juros Americanas 1979-2007

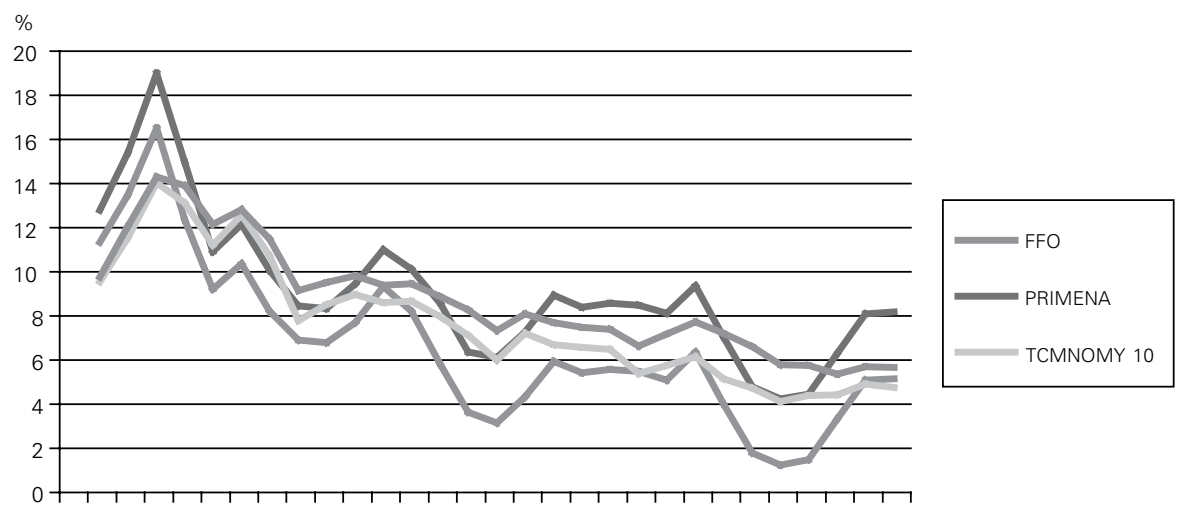

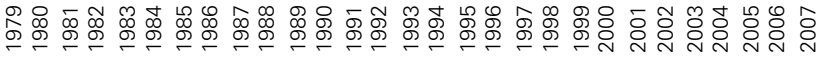

AAANA: MOODY'S YIELD ON SEASONED CORPORATE BONDS - ALL INDUSTRIES, AAA

PRIMENA: Average majority prime rate charged by banks on short-term loans to business, quoted on an investment basis FFO: Federal funds effective rate

TCMNOMY10: Market yield on U.S. Treasury securities at 10-year constant maturity, quoted on investment basis

Fonte: Federal Reserve

Elaboração: Núcleo de Economia e Política Externa

Gráfico 3:

Variação Percentual em Relação ao Período Anterior dos Gastos Federais

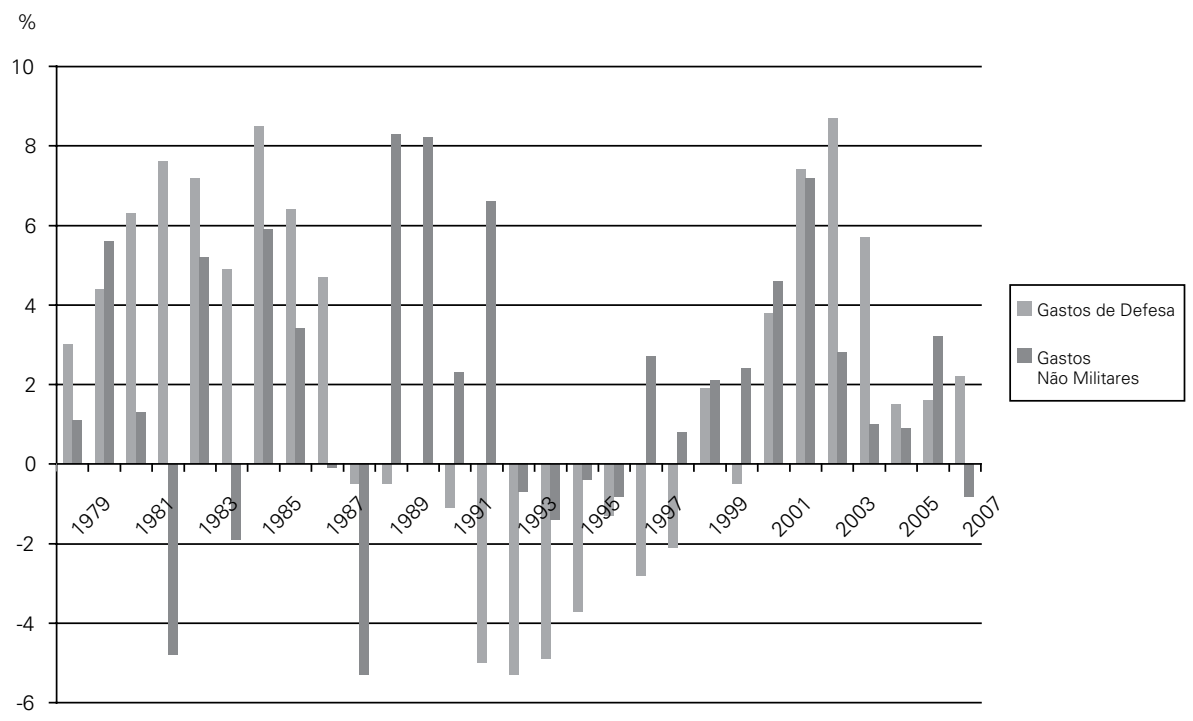

Fonte: U.S. Department of Commerce. Bureau of Economic Analysis

Elaboração: Núcleo de Economia e Política Externa 
Gráfico 4:

Resultado Líquido de Despesas e Receitas do Governo

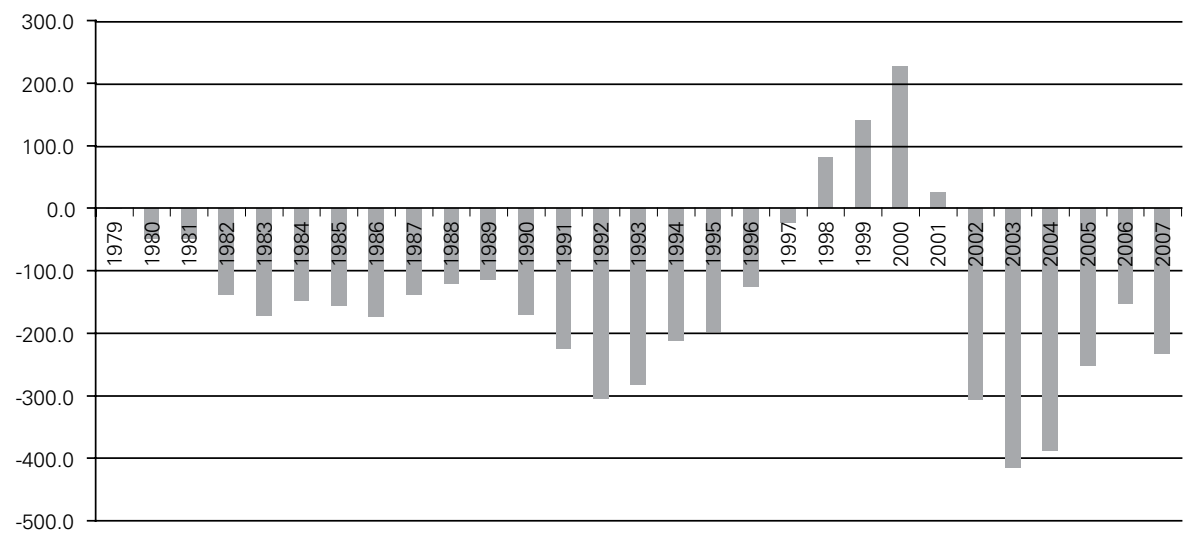

Fonte: U.S. Department of Commerce. Bureau of Economic Analysis Elaboração: Núcleo de Economia e Política Externa

Gráfico 5:

Conta-Corrente dos EUA (Bilhões de Dólares)

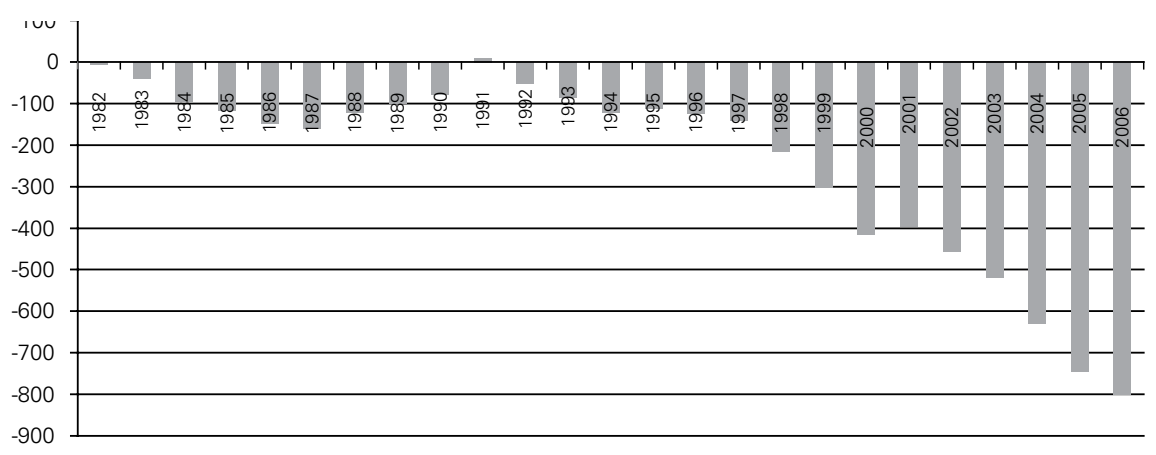

Saldo da Conta Corrente

Fonte: U.S. Department of Commerce. Bureau of Economic Analysis Elaboração: Núcleo de Economia e Política Externa 